\title{
The incidental lung lesion: effect of cardiac stress on the MIBI uptake in the lung mass
}

\author{
S. Farzanefar ${ }^{1}$, A. Mirzabeigi ${ }^{2}$, M. Abbasi ${ }^{*}$ \\ ${ }_{1}^{1}$ Department of Nuclear Medicine, Vali-asr Hospital, Tehran University of Medical Sciences, Tehran, Iran \\ ${ }_{2}^{2}$ Research Institute for Nuclear Medicine, Shariati Hospital, Tehran University of Medical Sciences, Tehran, Iran
}

- Case report

\author{
*Corresponding author: \\ Dr. Mehrshad Abbasi, \\ Fax: + 982166581529 \\ Email: meabbasi@tums.ac.ir \\ Revised: April 2015 \\ Accepted: May 2015 \\ Int. J. Radiat. Res., January 2016; \\ 14(1): 77-79 \\ DOI: 10.18869 /acadpub.ijrr.14.1.77
}

\begin{abstract}
A discrete $\mathrm{MIBI}$ avid lung lesion was found in cinematic views of myocardial perfusion imaging (MPI) of a 59 year-old woman. Interestingly, the abnormal uptake in the lung was detectable only in the rest phase images and not in the images acquired in the stress phase. MPI was performed for pre-operation cardiac risk assessment before correction surgery for spinal canal stenosis. She had no past medical history or symptoms concerning pulmonary problems. The clinical examination of the pulmonary system was normal. MPI was reported normal but for the lung lesion she was sent for consultation with pulmonologist. The pulmonologist diagnosed the lesion was an old inflammatory/infective lesion probably secondary to tuberculosis. No histopathological examination was done. By reporting this case we intended to highlight the possibility of the effect of stress on uptake of MIBI in tumoral lesions as a tumor agent in nuclear medicine.
\end{abstract}

Keywords: MIBI, tumor uptake, stress, myocardial perfusion imaging.

\section{BACKGROUND}

MIBI is a tumor agent used in nuclear medicine for years in evaluation of intrathoracic tumors (1) traditionally used for myocardial perfusion imaging (MPI)(2). It is recommended that MPI images should be reviewed for incidental uptakes in the entire field of imaging ${ }^{(3,4)}$ particularly in the sites of known tumors and inflammation (5,6). In MPI, extra-cardiac activities not only are of reconstruction concern but also may point out potentially treatable lesions (7-9). It is reported that dipyridamole stress exerts no significant change on the extracardiac uptake (10). The denoted extracardiac activities are not independent of the application of the stress. Here we present a case indicating the possibility of the negative effect of cardiac stress on uptake of the MIBI in the lung lesions.

\section{CASE PRESENTATION}

A 59-years old female patient was candidate for surgery on spinal canal stenosis. She had experienced lower extremity paresis and low back pain for months. She weighed 79 $\mathrm{kg}$ and also had exertional dyspnea with a one year history of hypertension. The pre-operation cardiac risk evaluation suggested further cardiac risk assessment with MPI.

Two day stress and rest protocol for MPI with 99m Technetium labeled MIBI was employed. MIBI injection was done 4 minutes after infusion of $0.56 \mathrm{mg} / \mathrm{kg}$ dipyridamol during 4 minutes. Imaging was done 45 and 90 minutes after tracer injection in stress and rest phases, respectively. SPECT data were acquired using a dual head Forte ADAC gamma camera (Philips, CA, USA) over $180^{\circ}$ circular rotation from the $45^{\circ}$ right anterior oblique position to the $45^{\circ}$ left 
posterior oblique position. ECG gated SPECT mode was employed with the following specifications: 32 stop; 30 second each stop; $64 \times 64$ matrix; and 8 bin for each cardiac cycle. Filter (ramp and Butterworth) back projection was done to reconstruct the short and long axis images for visual interpretation without attenuation correction.

There was no stress induced cardiac hypoperfusion and the MPI was reported normal. Nevertheless reviewing the row images of the SPECT there was a focus of MIBI uptake in the rest phase in hillum of the right lung (figure 1). The uptake was moderate to intense. Interestingly there was no remarkable abnormal uptake in this region in stress images (figure 2).
The patient was referred to pulmonologist and the final conclusion indicates the presence of an old inflammatory/infective lesion possibly due to tuberculosis.

\section{DISCUSSION}

We underscore the possibility of negative effect of stress on uptake of MIBI in tumoral or inflammatory lesions. MIBI uptake in tuberculosis is documented (11). Nevertheless the uptake is high possibly in active lesions in contrast to inactive tuberculosis or old lesions (12). Our finding may infer either presenting a case of MIBI uptake in an inactive tuberculosis

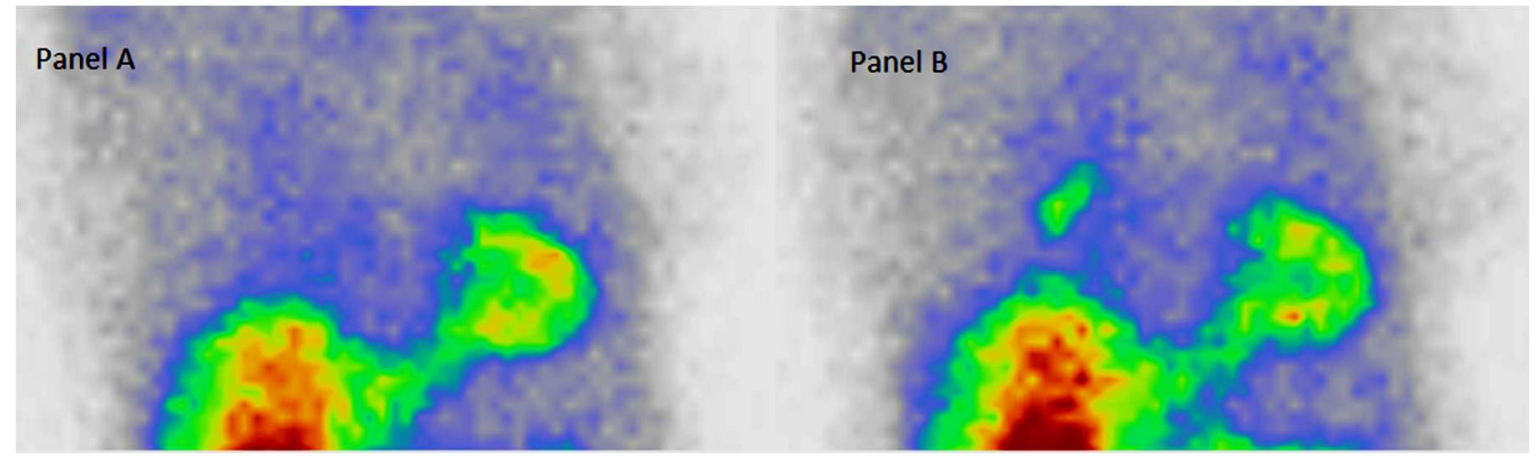

Figure 1. Anterior projection of the myocardial perfusion imaging of a 59 years old lady without history or symptoms of pulmonary disease; Normal uptake in lung fields in post stress (dipyridamol) image (A) but a single discrete lesion in the hilum of the right lung in rest phase (B).

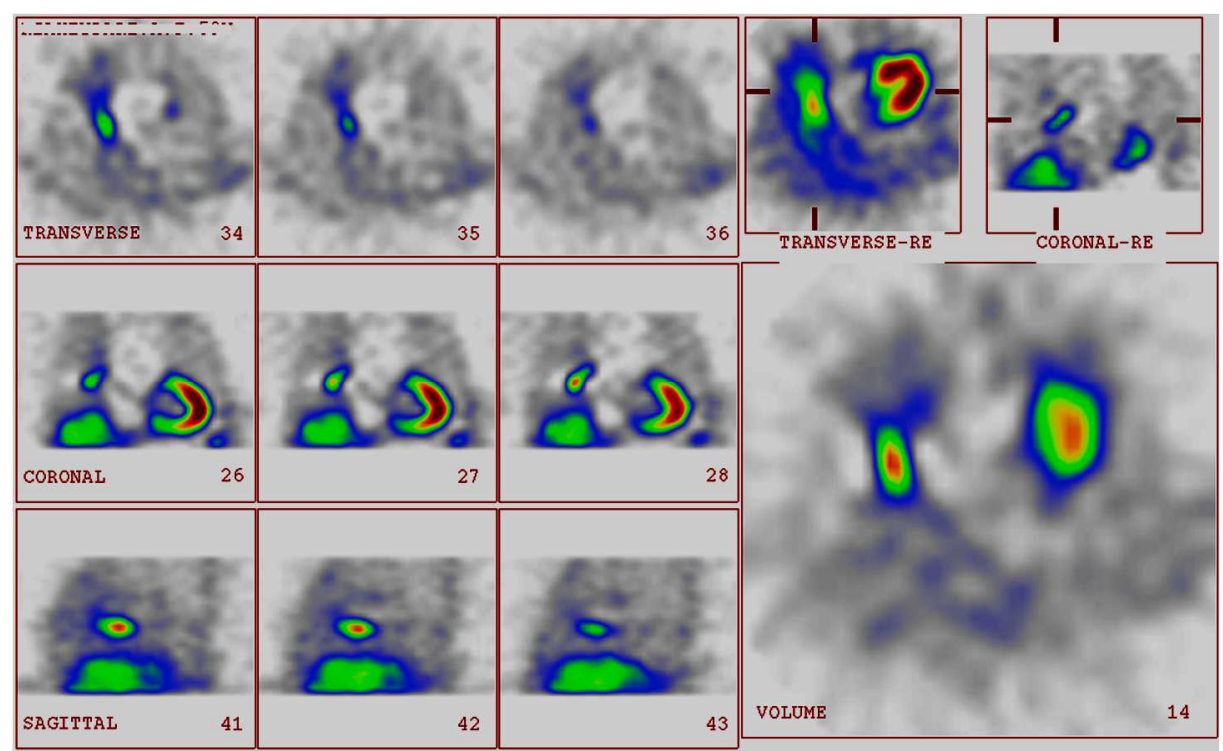

Figure 2. SPECT images of the chest of a 59 years old lady without history or symptoms of pulmonary disease at $20 \mathrm{mCi} 99 \mathrm{mTc}$ MIBI rest phase ; a discrete single lesion in the hilum of the right lung. 
or the wrong diagnosis of tuberculosis by pulmonologist. The mechanism of uptake for the MIBI in tumor and inflammatory sites is one or combination of the following: 1- augmented blood flow, 2- increased capillary permeability and 3- high metabolic activity of neoplastic cells which is strictly dependent on the cell and mitochondrial membrane potentials (13,14). The uptake in the lung lesion of the presented case was significant in rest images while there was no corresponding abnormality in the stress images. The patient had no drug history showing possible interference with the MIBI uptake. Based on the basic concept of the availability of the tracer for uptake in lesions (15) and the theoretical possibility of reduced perfusion of the extracardiac viscera in cardiac stress (15), we suppose that the cardiac stress has reduced the tracer availability for uptake in the mentioned lung lesion in stress phase secondary to increased coronary flow. This is the first time that the possible effect of stress on MIBI uptake in the lung lesions is reported. Certain reports indicate that the other tracer, MIBG, presents competition between the myocardium and the tumor cells with reduced heart uptake of MIBG in patients with MIBG avid tumors (16). Our finding is important either in the basic or clinical views. We suggest further clinical studies to clarify the subject.

\section{Conflicts of interest: none to declare.}

\section{REFERENCES}

1. Shih WJ, Rastogi A, Stipp V, Gross KK, Coupal JJ, Magoun S (1998) Tc-99m MIBI thoracic SPECT for the detection of intrathoracic tumor masses. Clin Nucl Med, 23(9): 594-600.

2. de Jong MC, Genders TSS, van Geuns R, Moelker A, Myriam Hunink MG( 2012) Diagnostic performance of stress myocardial perfusion imaging for coronary artery disease. A systematic review and meta-analysis, 22(9): 1881-1895.

3. Jones SE, Aziz K, Yasuda T, Gewirtz H, Scott JA (2008) Importance of systematic review of rotating projection images from Tc99m-sestamibi cardiac perfusion imaging for noncardiac findings. Nucl Med Commun, 29(7): 607-13. doi: 10.1097/MNM.0b013e3282f813f3.

4. Williams KA, Hill KA, Sheridan CM (2003) Noncardiac findings on dual-isotope myocardial perfusion SPECT. I Nucl Cardiol, 10(4):395-402.

5. Moretti JL, Hauet N, Caglar M, Rebillard O, Burak Z (2005) To use MIBI or not to use MIBI? That is the question when assessing tumor cells. Eur J Nucl Med Mol Imaging, 32(7): 836-42.

6. Bunyaviroch T, Aggarwal A, Oates ME (2006) Optimized scintigraphic evaluation of infection and inflammation: role of single-photon emission computed tomography/ computed tomography fusion imaging. Semin NuCl Med, 36(4): 295-311.

7. Sadeghi R, Kakhki VR, Zakavi R, Momennezhad M (2008) Gastroesophageal reflux detected on the myocardial perfusion scan with (99m)Tc-MIBI Hell. J Nucl Med, 11(3): 191-2.

8. Chamarthy M and Travin MI (2010) Altered biodistribution and incidental findings on myocardial perfusion imaging. Semin Nucl Med, 40(4): 257-70.

9. Williams KA1, Hill KA, Sheridan CM (2003) Noncardiac findings on dual-isotope myocardial perfusion SPECT. J Nucl Cardiol, 10(4): 395-402.

10. Rehm PK, Atkins FB, Ziessman HA, Green SE, Akin EA, Fox LM, Hixson DJ (1996) Frequency of extra-cardiac activity and its effect on 99Tcm-MIBI cardiac SPET interpretation. Nucl Med Commun, 17(10): 851-6.

11. Stefanescu C, Rusu V, Boişteanu D, Azoicai D, Costin M, Oleniuc D, Hurjui M, Sattish P (2006) 99mTc isonitrils biophysical aspects in pulmonary tuberculosis. Part I. In -vivo evaluation of $99 \mathrm{mTc}$ MIBI and 99mTc Tetrofosmin biophysical localization mechanisms. Rev Med Chir Soc Med Nat lasi, 110(4): 944-9.

12. Ahmadihosseini $H$, Sadeghi R, Zakavi R, Kakhki VR, Kakhki $\mathrm{AH}$ (2008) Application of technetium-99m-sestamibi in differentiation of active from inactive pulmonary tuberculosis using a single photon emission computed tomography method. Nucl Med Commun, 29(8): 690-4.

13. Santini M, Fiorello A, Mansi L, Rambaldi PF, Vicidomini G, Busiello L, Messina G, Nargi P (2008) The role of technetium-99m hexakis-2-methoxyisobutyl isonitrile in the detection of neoplastic lung lesions. Eur J Cardiothorac Surg, 35(2): 325-31.

14. Minai A, Raja SH, Mehta A, Sullivan EJ, Khan SU, Dasgupta A, Arroliga C (2000) Role of Tc-99m MIBI in the evaluation of single pulmonary nodules: a preliminary report, Department of Pulmonary and Critical Care Medicine, The Cleveland Clinic Foundation, 9500 Euclid Avenue, Cleveland, Ohio 44195, USA. Thorax, 55(1): 60-2.

15. Cox PH, Belfer AJ, van der Pompe WB (1976) Thallium 201 chloride uptake in tumours, a possible complication in heart scintigraphy. Br J Radiol, 49:767-768.

16. Suga K, Ogasawara N, Ariga M, Motoyama K, Hara A, Kume N, Matsunaga N (2000) Alteration of myocardial metaiodobenzylguanidine uptake after treatment of phaeochromocytoma and neuroblastoma. Eur J Nucl Med., 27(5): 574-82.

Int. J. Radiat. Res., Vol. 14 No. 1, January 2016 
